\title{
CRITICISM AND SILENCING IN ACADEMIA: THe Ambivalence OF FEedBACK
}

\section{Martin Lenz*}

\begin{abstract}
While criticism of management and other authorities might sometimes count as virtuous, it is often taken as a disturbance of business operations. Some people even think that criticism reflects badly on managers, as it supposedly shows that they do not have sufficient control over their employees. As I see it, then, feedback or criticism is framed in a highly ambivalent way: Although criticism is often invited as an opportunity for improvement, it is mostly received as a cause of reputational damage. A straightforward illustration of this fact is the treatment of so-called whistle blowers who might be viewed either as martyrs exposing problems to be addressed or as traitors revealing failings or misconduct. Yet, given the moral and institutional stakes in improving a problematic situation, it is still surprising that a portrayal of criticism as a disturbance is so often successful. So how is it possible to obscure the obvious downsides of shunning criticism? Zooming in on the ambivalent values associated with criticism, I shall argue that administrative hierarchies and distributions of tasks often provide incentives to suppress criticism and, by extension, collective action rooted in criticism of authorities in academia.
\end{abstract}

Keywords: Criticism, whistle blowing, hierarchy, management, universities

\footnotetext{
"Martin Lenz, University of Groningen, Faculty of Philosophy, Groningen, The Netherlands; e-mail: m.lenz@rug.nl | ORCID: 0000-0001-9342-6075
} 


\section{Introduction}

It is well known that transgressions such as harassment or other forms of misconduct in academia are often brushed under the carpet. This practice does not only require ill-intentioned perpetrators. It also requires that bystanders remain silent. J ohn Searle's sexual misconduct, for instance, went on for many years before being seriously challenged (Weinberg 2017). Assuming that such transgressions are mostly seen as blameworthy or at least problematic, it is worth asking why even people in the know remain silent. After all, bystanders in the know might end up being (called) complicit in malpractices. An obvious response is that bystanders are acting out of selfishness.

But many people also remain silent when their very own resources are threatened. While the ever-growing amount of cuts in higher education leads to vocal responses here and there, one might find it surprising that many staff members and students often remain quiet. So why do academics remain silent, even when their institutions are under threat? As long as there are some vocal activists, one might explain the silence by reverting to free riding. Relatedly, one might invoke obedience, the attitude of "just getting on with it" or the "culture of fear".

Ingrid Robeyns (2019), for instance, notes that the current silence in Dutch academia presents us with "a classical case of the collective action problem". But she adds that there is a "lack of an accessible, detailed analysis" that prevents us from overcoming the silence. This brief paper is not intended to provide such an analysis of the collective action problem. My rather modest aim is to contribute to it by taking a closer look at our collective silence.

My hunch is that at least some of the silence might be rooted in the way criticism is portrayed. While criticism of management and other authorities might sometimes count as virtuous, it is often taken as a disturbance of business operations. Some people even think that criticism reflects badly on managers, as it supposedly shows that they do not have 
sufficient control over their employees. As I see it, then, feedback or criticism is framed in a highly ambivalent way: Although criticism is often invited as an opportunity for improvement, it is mostly received as a cause of reputational damage. A straightforward illustration of this fact is the treatment of so-called whistle blowers who might be viewed either as martyrs exposing problems to be addressed or as traitors revealing failings or misconduct.

Yet, given the moral and institutional stakes in improving problematic situation, it is still surprising that a portrayal of criticism as a disturbance is so often successful. So how is it possible to obscure the obvious downsides of shunning criticism? Zooming in on the ambivalent values associated with criticism, I shall argue that administrative hierarchies and distributions of tasks often provide incentives to suppress criticism and, by extension, collective action rooted in criticism of authorities. In so doing, I will mainly focus on criticism within universities. While part of the explanations suggested might also extend to criticism of external authorities (such as governments), it is beyond the scope of this paper to address this point head-on.

I will begin by recalling some recent instances of the phenomenon (section 1) and move on to what I take to be the ambivalence of criticism (section 2). In view of this ambivalence, I will suggest that criticism of the status quo is associated with values that are rooted in the way we consider snitching (section 3). Then, I will identify ways of taming and obscuring criticism (section 4) and close with some concluding remarks.

\section{Collective Silence}

While the current corona crisis worsens the situation for almost everyone, it would be a mistake to think that the increase of cuts and threats to academia is owing to the pandemic. The year 2020 began with bad news for higher education. On a single day in J anuary alone three articles 
about manifest maltreatment of university staff came my way: The SOAS University of London "sacked all of its casualised academic staff in one go", the University and College Union published a report about "dehumanisation" of casualised staff, and a group of researchers on higher education published a paper revealing "an acute situation of endemic bullying and harassment, chronic overwork, high levels of mental health problems, general health and wellbeing problems, and catastrophically high levels of demoralisation and dissatisfaction" (Graham-Leigh 2020; McKie 2020; Erickson, Hanna, Walker 2020). While the current pandemic has certainly exacerbated the destruction of higher education, academics read such news a lot.

Although there are many good analyses of the political situation as such, the overall silence from colleagues strikes me as rather eerie. The silence, in turn, signals or translates into a lack of solidarity with those under immediate threat. Nowin view of the articles listed above and the strike actions taking place every now and then, you might think that the community is rather vocal but merely not very successful.

Yet, my impression is that academia is facing a lot more problems than the number of articles and protests suggests. Looking at the situations worldwide, it is clear that universities are under threat in many places: Hungary, Brazil and Australia look particularly bad, but Turkey, Romania, the US and many other places seem to fare no better, when it comes to systematic attacks on higher education practices. The articles mentioned above are about the UK. I am writing from the Netherlands. While the Dutch system struck me as fairly good on arrival in 2012, I begin to see rather worrying signs.

What was not obvious to me on arrival but becomes clear when looking at the figures provided by The Association of Universities in the Netherlands (VSNU) is that the last twenty years have seen an increasing structural underfunding of universities by the government: While enrolments continue to rise, the government funding per student has declined by $25 \%$ since 2000 (VSNU n.d.). One of the latest moves was 
to reallocate the budget from Medicine and the Humanities to the technical and natural sciences, which are mainly hosted at the four technical universities (NL Times 2019). In the light of such changes, it strikes me as pure cynicism when the Dutch Minister of Education expresses the hope that the situation will be ameliorated in five to ten years, so that then academics may be able to do their jobs "within normal working hours" again (Matthews 2020).

However, while budget cuts are threatening, they might appear to be an external political threat, likely to leave individual staff members and students with the impression that the powers behind these developments are ubiquitous but difficult to address. If you think that you need to be up against "capitalism" at large, you might easily feel powerless. Therefore, it is vital to see how such abstract threats translate into the situation "on the ground". As I see it, such cuts result in an academic business model that incentivises even more competition in research, on the one hand, and casualises teaching through allocating it increasingly to temporary teaching-only staff, on the other.

Rather than forming a unity, then, teaching and research (or rather the pertinent performance indicators) are played off against one another. What might sound somewhat abstract clearly translates into a problematic situation on the ground: Academics work more and more hours, and encounter colleagues working under increasingly precarious conditions; they find students who begin to worry about employability from day one and who emulate the competition among their supervisors; they find administrators who, while trying to make ends meet, are increasingly targeted by complaints that they have no real power to address.

Given that the political threats clearly translate into our every-day encounters, it might seem surprising that we find very little explicit criticism of higher management and government. Why? To some degree, all stakeholders involved will try to cope and rationalise this situation. 
Given the priority of research, the casualisation of teaching and its increasing dissociation from research might well be seen as part of the business model of universities, competing for income by assuring reputation through pertinent rankings. Since such a business model does not exist in isolation but within society at large, it might appear as unavoidable for the time being, even if it yields undesired results.

Of course, no one really seems to want the overall decline and casualisation of teaching. But it will get portrayed as an undesired side effect of our focus on research. At this point, however, we have already forgotten that what is being measured most of the time is not really research but performance indicators, in other words: jumping through hoops. J umping through hoops and worries about failing to do so naturally seem to block collective action and promote silence instead. ${ }^{1}$ Mariya Ivancheva (2018) describes this as follows:

"It is quite difficult to unite and organize resistance around a common cause while higher education has a huge reserve army of workers on precarious fixed term and fractional contracts, unsure if they will have secure employment and bread on their table in a few months. And this while even permanent academics feel ever more vulnerable and threatened..."

Dutch academia is currently addressing this issue in the guise of overwork. While overwork was already a topic a while ago, the government's reallocation plans for universities mentioned above have dried up many means and measures thought out for balancing the situation. In J anuary 2020, Ingrid Robeyns (2020) described the situation as follows:

"Colleagues report negative effects on their mental and physical health, sleep deprivation, constant worrying, deterioration of their friendships and other social relations, insufficient time for self-care including doing exercise, and so forth. The main problem is that the notional hours that are given to teach a course or do supervision (...) are inadequate, and hence a $70 \%$ teaching load leads to a more-than-fulltime workload. And

\footnotetext{
' See: Enders, Westerheijden 2017 for a nuanced account of reforms in Dutch HE.
} 
since everyone also wants to, needs to, and/ or is expected to do research, that also still needs to be done. Add some administration and/ or leadership tasks, and societal outreach, and we easily make 55 hours a week. For colleagues who only teach, and who are on the lowest pay scales, this also means they have troubles buying a house or starting a family, since those contracts are almost always part-time, and hence also create financial stress. (...) [T]he Minister of Higher Education has acknowledged that the universities need a structural increase of their yearly budgets with 1.000.000.000 Euro (one billion!) but she claims she doesn't have that money available."

If this sounds really bad, imagine how the situation has changed by now during the on-going corona crisis. You would think that this would have created some momentum, but it did not, at least not in large numbers. Why not? As noted, an obvious reason might be that self-interest stops people from voicing criticism, especially if the threats seem fairly abstract or still a bit remote. But the criticism I have in mind would not only concern the government. As we have seen, the governmental policies eventually translate into very concrete encounters with effects on the ground. At least on this level, a great number of people are directly affected, be it through increasing overwork or increasing casualisation. If we say that rationalisation and other coping strategies explain why people carry on without much ado, we still need to explain what hinders due criticism.

\section{The Ambivalence of Criticism}

As noted earlier, there are probably a number of different factors that promote silence and hinder criticism. Seen this way, we could simply assume that criticism is portrayed only in negative terms and is thus not really counted as a viable way of improvement. But this cannot be right, since academia in particular thrives on criticism. Thus, even people in supervision or managerial roles will commonly not only tolerate but 
also invite criticism. One might object that such authorities act in bad faith, but I doubt that this is a fruitful explanation. As I shall argue now, criticism as such is neither negative nor positive. Rather, criticism is presented in a highly ambivalent manner. What we need to make sense of is that criticism is typically invited for reasons of improvement, while it is often taken as a cause of reputational damage. Yet, given that it is not the critic but the process criticised that actually causes the damage, the ambivalence as such doesn't explain why criticism is taken to reflect badly on the critic. This fact, I will suggest, is owing to an underlying ambivalence of values attached to criticism: values attached to telling the truth versus the values attached to snitching or telling on someone. However, let's begin by looking at the upside.

On the face of it, one could assume that criticism of policy is mainly seen as a means to spot problems or weaknesses in a system. Accordingly, criticism would be welcome as a positive engagement that helps improving processes and results. In this sense, it is indeed often invited under the name of "feedback". Arguably, giving feedback is one of the core businesses in academic work in that we critically engage with the work of colleagues and students all the time. One might object that academic criticism proper, as it were, concerns one's professional specialisation and work. By contrast, criticism of procedures or management is mostly alien to one's competence.

However, this line of reasoning is problematic for several reasons. Firstly, academic criticism in one's own area has also costs and is therefore not always welcome. ${ }^{2}$ Secondly, many administrative procedures directly concern academic teaching and research, and are pertinently carried out by academics themselves. While it is true that we mostly learn administrative work on the job rather than through instruction, the tight relation of such procedures to our core tasks affords us a spe-

${ }^{2}$ Arguably, the adversarial forms of criticism in some fields produce indeed problematic costs (see: Lenz 2020). 
cial competence in these areas, too. For this reason, it strikes me as sensible that academic and administrative staff work hand in hand, as is in fact often the case. Such collaboration has become ever more refined and by now we have created whole systems of processing feedback for the handling and improvement of tasks.

We will return to such feedback and evaluation systems in the next section, but for now we might conclude that criticism does have a positive role to play. Related to values such as accountability and transparency, feedback from staff and students is regularly collected, at least at my university where we now have an annual survey for staff and PhDs in addition to student feedback via the advisors and evaluations. Speaking from personal experience as a staff member and department chair, I have the impression that both student and staff feedback is indeed mostly valued and acted upon. Therefore, I can acknowledge that criticism, provided as feedback in pertinent cycles, is welcome and connoted with positive values of truthfulness and loyalty.

Let's now look at some negative factors of criticism. In exposing problems, criticism is not only an occasion for improvement but also a cause of reputational damage. But which factors are crucial in seeing criticism in such a negative light? One such factor might be competition. As noted earlier, many whistle blowers are ostracised and need protection that sometimes seems rather difficult to come by, to put it mildly. But we do not need to focus on complex cases such as that of Edward Snowden. In our daily academic interactions we might find that sometimes criticism seems mainly intended to devalue our work. While such criticism might still expose a shortcoming in an academic paper, we might feel threatened because the exposure reflects badly on our competence. Since we interact at once as academic colleagues and as (potential) employees, criticism can at least sometimes be seen as causing reputational damage. It is plausible to assume, then, that the incentives for competition about jobs in a zero-sum game amplify the negative effects of criticism. While even a fierce critic might actually earn some 
reputation in an academic setting, this effect can be reversed in straightforward employment relations. Thus, it is important to note that the often tacit oscillation from academic to managerial authority and back can have very confusing effects. Your colleague might appreciate criticism of her paper but resent feedback of her management once she's back in her role as your department chair.

It is not obvious to me what explains this difference. My hunch is that the respective criticisms relate to different kinds of vulnerabilities. As scholars or scientists we might feel unique to some degree, at least insofar as a certain kind of work we do cannot be done by anyone else in the same way. By contrast, as employees with or without managerial roles we can be potentially replaced from one day to the next. Thus, in extreme cases, criticism of our conduct as employees might indeed lead to our being replaced. "Being a colleague" has a twofold nature, then, in that it comprises both kinds of relations at once. So in a competitive system like academia, spotting weaknesses is likely turned against the critic: If you spot a weakness in the system, your manager might retort that you are too weak for the system. The so-called selection of the "best" incentivises such a view insofar as it favours those who display loyalty through extra efforts. Thus, it is not surprising that academics still pride themselves for overwork. Arguably, academia is therefore often driven by the pretence that everything is just fine, leading to selfexploitation, on the one hand, and to ostracisation of critics, on the other.

Yet, in our daily interactions we rarely hit on extreme cases; nor does criticism necessarily target a single person. If I say that some process is not going very well, such a remark often concerns a number of people and quite often even targets myself. So I doubt that competition alone explains the shunning of critics. A second factor might be that political criticism in universities is often framed as an indication of left-leaning biases or even as what is called "Cultural Marxism". Accordingly, criticising the system can be framed as a political attitude that is deemed 
unfit for academics, who are taken to be sworn to dubious standards of neutrality.

It is this topos of supposed leftism in particular that might explain why academics do not merely shun internal criticism of management, but also often refrain criticising the government for the underfunding of the universities. I cannot make an extensive case here, but my hunch is that this topos allows for framing criticism of structural underfunding as a political claim rather than a call for structural institutional support: An academic wishing to address overwork might then find herself portrayed as a leftie unduly asking for more of the taxpayers' money. Once you get away with the claim that academics are political partisans, requesting structural support in academia can be reframed as political partisanship. If you want a whiff of this just listen in on Trump likening climate scientists to "foolish fortune tellers".

As I see it, the point of this move is not merely to attack scientists, but to insinuate that demands of academics are owing to political partisanship, and thus delegitimise criticism of the government. This shunning of "the left" has of course a long tradition and goes often hand in hand with rendering institutions that represent employers suspicious. While trade unions, for example, often take it upon them to negotiate and maintain crucial employment rights, they have surprisingly few members in academia. (This fact might partly be owing to the fear of being frowned upon for supporting critics of "the system".) Yet, although representations of employment rights might have a troubled history, the topos of "leftism" does not strike me as a factor that has much credence inside academia. ${ }^{3}$ However, my point is not to decide whether or not academics are more left-leaning than other professionals. Rather, my point is that this topos can be instrumental in shunning criticism of the government, namely by enabling the reframing of requests for funding as owing to a political agenda.

3 See: Gilbert (2020) for Trump's remarks. A nuanced study and assessment of left-leaning opinions among academics is provided by van der Werfhorst (2019). 
Considering the twofold nature of collegial relations, we havealready touched on a third factor: Besides the academic hierarchies from student to professor we encounter employment hierarchies reaching from student assistant to president or rector. Whereas academic hierarchies are closely tied to professional academic education and training, employment hierarchies are not or not necessarily in line with this. A successful senior academic is not necessarily a good manager or leader. Conversely, a successful manager is not necessarily a good scholar or scientist. However, reputation can come within both hierarchies, which often leaves these hierarchies intertwined. Arguably, it is this intertwinement that makes the criticism (especially of internal hierarchies or processes related to them) ambivalent.

The ambivalence seems to be rooted in an on-going tension between the hierarchies: While they are intertwined, they are founded on very different lines of justification. Even if the academic and managerial qualities actually happen to coincide, the different hierarchical orders are not equally justifiable to the respective colleagues. If I happen to be your department chair, this authority weighs nothing in the setting of, say, an academic conference.

As Lisa Herzog has shown, the justification of hierarchies is a morally delicate matter that certainly affects our daily transactions. Assuming that people in an academic setting all have an equal moral standing, it is a basic question what kind of hierarchies count as justifiable in the first place. This question is particularly pressing in what is called "managerialism" or "new public management", a pervasive approach within many academic institutions. Even if there are "beneficial forms of cooperation" that "require coordination through hierarchies", the "managerial approach relies on goals and objectives decided upon by other agents than those who do the actual work" (Herzog 2017)4. This means that hierarchies might be justifiable in principle.

4 The Dutch system has gradually implemented such an approach since the 1980s. See on the history of Dutch management in: Enders, Westerheijden 2017. 
But while the goals of academic work and thus hierarchies are to some degree in the control of the actual agents involved, managerial hierarchies cannot be justified in the same way. A helpful illustration is the way qualitative and quantitative assessment of our work come apart: A single paper might take years of research and end up being a game-changer in the field of specialisation, but if it happens to be the only paper published in the course of three years, it will not count as sufficient output. So while my senior colleague might have great respect for my work as an academic, she might find herself confronted with incentives to admonish or sanction me in other ways.

What does this mean for the status of criticism? The twofold nature of hierarchies leaves us with two entirely disparate justifications of criticism. If my colleague critically assesses my work, her criticism will appear academically inadequate but managerially apt. Now these disparate lines of justification are themselves a constant reason for criticism. The fact that a field-changing paper and a mediocre report both make one single line in a CV bears testimony to this. At the same time, we seemingly delegitimise this reason by tolerating and ultimately accepting it. Of course, most academics are aware of this tension: the quantification of our work is an almost constant reason for shared grievance. But as employees, we find ourselves often enough buying into it as a "necessary evil". Now, if we accept it as a necessary evil, we seem to give up on our right to criticise it. Or don't we? Of course not, and the situation is a lot more dynamic that I can capture here. To understand how "buying into" an imperfect situation (a necessary evil) might seemingly delegitimise criticism, it is crucial to pause and briefly zoom in on the shared grievance I just mentioned. Let me explain.

\section{Criticism as Snitching}

I will now try to sketch how this shared grievance constitutes our status quo and, in turn, provides social cohesion among academics. Criticism 
will turn out to be a disturbance of that social cohesion. Thus, critics of the status quo will likely be ostracised as "telling on" us.

One might portray the fact that we live with an academic and a managerial hierarchy simply as unjust. One hierarchy is justified, the other is not. Perhaps, in a perfect world, the two hierarchies would coincide. But in fact we accept that, with academia being part of the capitalist world at large, they will never coincide. This means that both hierarchies can be justified: one as rooted in academic acclaim; the other as a necessary evil of organising work. If this is correct and if we accept that the world is never perfect, we will find ourselves in an on-going oscillation and vacillation. We oscillate between the two hierarchies. And we vacillate between criticising and accepting the imperfection of this situation.

This vacillation is, I submit, what makes criticism truly ambivalent. On the one hand, we can see our work-relations from the different perspectives; on the other hand, we have no clear means to decide which side is truly justified. The result of this vacillation is thus not some sort of solution but a shared grievance. A grievance acknowledging both the injustices and the persisting imperfection. There are two crucial factors in this: the fact that we accept the imperfect situation to some degree; and the fact that this acceptance is a collective status. It is the status quo. Now, I alone could not accept the on-going injustice, if my colleagues were to continuously rebel against it. Thus, one might assume that, in sharing such an acceptance, we share a form of grievance about the remaining vacillation.

It is of course difficult to pin down such a phenomenon, as it obtains mostly tacitly. But we might notice it in our daily interactions when we mutually accept that we see a tension, for instance, between the qualitative and quantitative assessment of our work. This shared acceptance, then, gives us some social cohesion. We form a group that is tied together neither by purely academic nor by purely managerial hierarchies and relations. There might bea growing sense of complicity in dynamic 
structures that are and are not justified but continue to obtain. So what forms social cohesion between academics are not merely factors of formal appraisal or informal friendship. Rather, a further crucial factor is the shared acceptance of the imperfection of the status quo. It is crucial in that it acknowledges the vacillation and informs what one might call the "morale" of the group. 5

If this is correct, academics do indeed form a kind of group through acceptance of commonly perceived imperfections. Now if we form such a group, it means that criticism will be seen as both justified but also as threatening the shared acceptance. We know that a critic of quantitative work measures is justified. But we also feel that we gave in and accepted this imperfection a while ago. The critic seemingly breaks with this tacit consent and will be seen like someone snitching or "telling on us".

As I see it, it is this departure from an in-group consensus that makes criticism appear as snitching. And while revealing a truth about the group might count as virtuous, it makes the critic seemingly depart from the in-group. Of course, companies and universities enjoy also some legal protection: Even if you find out about something blameworthy, you might be bound by rules about confidentiality. This is why whistle blowers do indeed have an ambivalent reputation, too. But I guess that the legal component alone does not account for the force of the in-group mentality at work in suppressing criticism.

As we noted earlier, the twofold hierarchy might even come with inverse perceptions of criticism: your professorial colleague might be happy to learn from your objections, while your department chair might shun your criticism and even retaliate against you. Yet, they might be the same person. Considering the ubiquitous histories of suppressing critics of sexism, racism and other kinds of misconduct, we do not need to look far to find evidence for ostracism or retaliation against critics. ${ }^{6}$

5 On the factor of emotional cohesion see: Bollen and Hoyle (1990).

${ }^{6}$ See, for instance, the blog What is it like to be a woman in philosophy Blog. 
I think that it's hard to explain this level of complicity with wrongdoers merely by referring to bad intentions, on the one hand, or formal agreements such as confidentiality, on the other. Rather, I think, it is worthwhile to consider the deep-rooted in-group consensus that renders criticism as snitching. One reason is that snitching counts, at least in a good number of cultures, as a bad action. But while this might be explained with concerns about social cohesion, it certainly remains a dubious verdict, given that snitching is truth-conduciveand should thus be aligned with values such as transparency. Going by personal anecdotes, however, I witnessed that snitching was often condemned even by primary school teachers, who often seemed worry about social cohesion no less than about truthfulness. ${ }^{7}$ In other words, we don't seem to like that the truth be told when it threatens our status quo.

In sum, we see that the ambivalent status of criticism is rooted in a twofold hierarchy that, in turn, comes with disparate sets of values. Shared acceptance of these disparate sets as an unavoidableimperfection binds together an in-group that will sanction explicit criticism of this imperfection as a deviation from the consensus. ${ }^{8}$ If we ask what makes theinclinations to sanction in-group norm violations so strong, it seems helpful to consider the deep-rooted code against snitching. While the moral status of sanctioning snitching is certainly questionable, it can shed light on the pervasive motivation and strikingly ready acceptance of such behaviour.

\section{The Taming of Criticism}

With this perspective in place, we should ask whether criticism does ever appear justified. If there really is a consensus about imperfection, and I think there is, then it is really difficult to raise criticism unless it

7 On the ethics of snitching see: Kleinig (2017) and Davies (2003).

${ }^{8}$ Arguably, the current charges against so-called "virtue signalling", a "call out culture" or "cancel culture" on social media strike can as instances of such sanctions. On virtue signalling see: Levy 2020. 
is explicitly called for. Why? Let's recap: The ambivalence of criticism in academia is mirrored in the ambivalent status we ascribe to snitching among children and adolescents. Yes, people telling on others might point out problems, but the selfish reasons we suspect behind such snitching are seen as a threat to the social cohesion of the in-group. This means that an act of criticism, especially when it concerns management, needs a justification that decouples it from the potential association of snitching.

To give a simple illustration: If you continuously walk around and tell our colleagues out of the blue (and without further evidence) that I am an incompetent leader or that I am guilty of harassment, they will at some point take you be motivated by selfish reasons and probably think that you just want to do me down to appear in a better light yourself, at least after a while. Consider this example carefully: The criticism in this kind of context is not suspicious because it is revealed to be unfounded. It is suspicious because it is not called for. Unless further evidence is provided, you are not seen as someone trying to rectify the situation. Most people will see you as disturbing the social order. (The stakes might change of course, if you also claim to be a victim. But in this you are providing at least a bit of evidence, your own victimisation.)

This means that criticism can be justified in two different ways: Firstly, it can be justified by corresponding to facts; secondly, it can be justified by being called for. Of course, both justifications can obtain, but against the backdrop of a consensus about imperfection it is hard to be taken seriously, if the criticism is not called for. Why? Because we already assume that things are not perfect. If you claim that someone's behaving badly, this is nothing out of the ordinary. In fact, it conforms to our expectations. So the main suspicion is: Why do you bring it up?

It would be interesting to pursue what precisely explains such behaviour, but for the time being we can take it as variant of the so-called 
bystander effect ${ }^{9}$ and focus on the second kind of justification. While blurting out criticisms as a constant gossip might raise suspicions, there are moments when criticism does appear justified. When someone explicitly asks you to voice your opinion, for instance, even harsh criticism might appear justified because it is invited by the question rather than driven by seemingly selfish motivations.

If this is correct, criticism loses its negative connotation if it is asked for. But what does "being asked for" amount to? Do we need an explicit question or is the display of moral motivation sufficient? As we learn from the arguments about virtue signalling, the latter does not seem to be sufficient for everyone. Universities do of course recognise that criticism, even criticism of management, is a crucial factor for improvement of performance. As we have seen, criticism is not necessarily problematic. While academic criticism is often portrayed as a positive element, criticism of management leaves the criticised managers more vulnerable, because their management roles have been less justified in the first place. So criticism of management in academia comes with two main problems: If not asked for, it reflects badly on the critic; if it targets the manager, it exposes vulnerabilities. Taken together, these aspects place a high hurdle on criticism that is perceived as justified or acceptable. So how can criticism be integrated in our daily practices without raising undue suspicions?

A first solution emerges if we look at the way universities actually tackle this problem. The general strategy is to depersonalise criticism and have it focus on the processes. Student evaluations and personnel surveys are mostly anonymous and thus protect the critic. At the same time they target not only the performance of a person but also wider factors of the work or learning environment. This protects the person

9 Invoking the so-called bystander effect, psychologists explain people refraining from supporting victims by the presence of other people who could possibly help. See for instance: Fredricks, Ramsey, Hornett 2010. 
criticised in that they are not the sole focus of blame. ${ }^{10}$ Most importantly, the criticism is justified because it is indeed asked for. In this sense, the suspicious nature of criticism can be tamed. Further moments for bringing up criticism are provided in performance interviews and the various committees which allow for a more direct collegial exchange.

However, all these forms have clear downsides: They leave the control of the time and the mode of reception of criticism entirely in the hands of the management. Thus, offering criticism is not an act between equals. This is not only a problematic denial of agency for the critic. It also hinders an identification of what is actually targeted by the criticism. To see this, imagine that you regularly do the family shopping. But instead of being told right away that you forgot to buy cheese, you receive a statistical survey of what went wrong every three months. Neither would there be occasion for a clear identification of the problem, nor a proper exchange in which you could alleviate mutual grievances. This way, criticism can be and often is obscured. While this might protect the agents, it also blocks them from coming forward to address issues head-on.

If this is correct, it strikes me as important to look for solutions that accommodate the ambivalence of criticism. This would mean first of all to recognise criticism of management in good faith for what it is: Most of the time criticism is not an attempt to "tell on" weak managers, but to ameliorate the situation for everyone involved by pointing out problems. The crucial ingredient in all relationships, be they academic, managerial or personal, is trust. And trust requires mutual interaction. Surveys and evaluations reveal important information about more widespread patterns of opinion and mood. But they leave the control onesided and offer only a third-person-perspective on the group. Thus, this

${ }^{10}$ Detracting from blaming seems a duly considered albeit not entirely unproblematic choice in policymaking, see: Lupton and Warren 2016. 
practice would need to be complemented by a trustful mode of interaction that restores agency for all participants involved.11

\section{Concluding Remarks}

I hope to have shown how the ambivalence of criticism might figure in an explanation of silence in the workplace. Starting from external threats against higher education and sketching how they can play out in the academic workplace, I have argued that criticism is often ambivalent. Being rooted in larger societal norms, the ambivalence seems to be rooted in the intertwinement of two different value sets: that of truthfulness and that of snitching. If we assume that the current status quo also rests on an acceptance of imperfection, criticism - it seems - needs a special justification to get off the ground. While universities try to accommodate this by implementing pertinent surveys, the impersonal character of such devices deprives criticism of its core function, i.e. enabling the interlocutors to address problems head-on.

Focussing on criticism among academics in different roles, the paper largely confined itself to internal criticism. As noted in the introduction, focussing on criticism of authorities within universities leaves open the question of whether the explanations suggested carry over to external criticism, for instance, of governments. While I doubt that there is one explanation that holds across the board, I think that the mechanisms aiding to shun internal criticism might go hand in hand with more general ways of delegitimising criticism. As noted earlier, my hunch is that it is the topos of the left-leaning academic in particular that can be instrumental in shunning criticism of the government, namely by enabling the reframing of requests for funding as owing to a political agenda.

While the present paper can only gesture at solutions, I would hope that further focus on the ambivalent value sets behind criticism and

$"$ On forgiveness in the workplace see: Aquino et al. 2003. 
feedback helps us understanding the problem of collective action better and eventually provides suggestions for eventually overcoming the collective silence.

Acknowledgements

Following a discussion of a blog post on silence in academia (Lenz 2019), Izabela Wagner kindly invited me to contribute to this issue. I am enormously grateful to her for the exchanges and for providing this opportunity. Moreover, I have benefitted greatly from advice by Lisa Herzog, Pietro Ingallina, Mariya Ivancheva, Christopher Quinatana, Rineke Verbrugge, and the comments of two anonymous referees.

References

Aquino, K., Grover, S., Goldman, B., Folger, R. (2003). When Push doesn't Come to Shove: Interpersonal Forgiveness in Workplace Relationships. Journal of Management Inquiry, 12. 209-216. https:/ / doi.org/ 10.1177/ 1056492603256337

Bollen, K., Hoyle, R. (1990). Perceived Cohesion: A Conceptual and Empirical Examination. Social Forces, 69(2). 479-504. https://doi. org/ $10.2307 / 2579670$

Davies, D. (2003, 18 July). Snitch!. Crooked Timber Blog. https:// crookedtimber.org/2003/ 07/ 18/ snith/ [November 20, 2020]

Enders, J., Westerheijden, D. (2017). The Dutch way of New Public Management. Policy and Society, 33(3), 189-198. https:// doi.org/ 10.1016/j.polsoc.2014.07.004

Erickson, M., Hanna, P., Walker, C. (2020). The UK higher education senior management survey: a statactivist response to managerialist 
governance. Studies in Higher Education. https:// doi.org/ 10.1080/ 03075079.2020 .1712693

Fredricks, S., Ramsey, M., Hornett, A. (2010). Kinship and Bystander Effect. Journal of Religion and Business, 2.

Gilbert, D. (2020, 21 J anuary). Trump just called climate scientists 'foolish fortune tellers'. Vice News. https:// www.vice.com/ en/article/ 3a8dz8/trump-just-called-climate-scientists-foolish-fortunetellers [November 20, 2020]

Graham-Leigh, E. (2020, 20 J anuary). SOAS just sacked effectively sacked all of its casualised staff in one go. Counterfire. https:// www.counterfire.org/ news/ 20841-soas-just-effectively-sacked-allof-its-casualised-academic-staff-in-one-go [November 20, 2020] Herzog, L. (2017). What's wrong with managerialism? Work hierarchies and control from a relational egalitarian perspective (unpublished manuscript).

Ivancheva, M. (2018). At Stake Is the Future of Public Higher Education. Interview of D. Nehring with Mariya Ivancheva. Social Science Space Blog. https://www.academia.edu/36550805/At_Stake_is the_Future_of_Public_Higher_Education_Interview_of_Daniel Nehring_with_Mariya_Ivancheva [November 20, 2020]

Kleinig, J. (2017). Loyalty. Stanford Encyclopedia of Philosophy. https:/ / plato.stanford.edu/ e.ntries/ loyalty/ \#WhisBlow [November $20,2020]$

Lenz, M. (2020, 8 J anuary). The adversarial culture in philosophy does not serve the truth. Aeon Magazine. https:// aeon.co/ideas/the-adversarial-culture-in-philosophy-does-not-serve-the-truth [November 20, 2020]

Lenz, M. (2019, 22 January). Silent academics and the decline of (higher) education. Handling Ideas Blog. https://handlingideas. blog/ 2020/ 01/ 22/ silent-academics-and-the-decline-of-higher-education/ [November 20, 2020] 
Levy, J . (2020, 29 November). Is virtue signalling a perversion of morality. Aeon Magazine. https:// aeon.co/ ideas/is-virtue-signalling-aperversion-of-morality [November 20, 2020]

Lupton, B., Warren, R. (2016). Managing without blame? Journal of Business Ethics, 152. 41-52. https://doi.org/10.1007/s10551-0163276-6

Matthews, D. (2020, 17 September). Dutch education minister wants academics to have weekends. Inside Higher Education. https:/ / www.insidehighered.com/news/ 2020/ 09/ 17/ dutch-education-minister-wants-academics-have-weekends [November 20, 2020] McKie, A. (2020, 20 J anuary). Casualised staff 'dehumanised' in UK universities. Times Higher Education. https:/ / www.timeshighereducation.com/news/ casualised-staff-dehumanised-uk-universities [November 20, 2020]

NL Times (2019, 15 May). Change the way money is distributed among universities. https:// nltimes.nl/2019/05/15/ change-way-moneydistributed-among-universities-technical-universities-govt-advice [November 20, 2020]

Robeyns, I. (2019, 15 March). Lessons from Dutch academic activism. Crooked Timber Blog. https:/ / crookedtimber.org/ 2019/03/ 15/lessons-from-dutch-academic-activism-part- $1 /$ [November 20, 2020] Robeyns, I. (2020, 20 J anuary). The consequences of overtime in Dutch academia. Crooked Timber Blog. https:/ crookedtimber.org/ 2020/ $01 / 20$ / the-consequences-of-overtime-in-dutch-academia/ [November 20, 2020]

Weinberg, J. (2017, 11 April). UC Berkeley knew of prior complaints about Searle. Daily Nous Blog. http:// dailynous.com/2017/ 04/11/ uc-berkeley-knew-prior-complaints-searle/ [November 20, 2020] What is it like to be a woman in philosophy Blog. https:// beingawomaninphilosophy.wordpress.com/ [December 16, 2020]

van der Werfhorst, H. (2019). Are Universities Left-Wing Bastions? The political orientation of professors, professionals, and managers in 
Europe. The British Journal of Sociology, 71(1). 47-73. https:// doi. org/ 10.1111/ 1468-4446.12716

VSNU (n.d.). Dalende rijksbijdrage. https://vsnu.nl/dalende-rijksbijdrage.html [November 20, 2020] 